\title{
Analisis Pengaturan Layout Gudang Sparepart Menggunakan Metode Dedicated Storage di Gudang Bengkel Yamaha Era Motor
}

\author{
Imelda Agustina \\ Program Studi Manajemen Logistik, Institut Ilmu Sosial dan Manajemen STIAMI \\ Jl. Pangkalan Asem Raya No. 55, Cempaka Putih, Jakarta Pusat, Indonesia \\ Imeldaagustin254@gmail.com \\ Resista Vikaliana* \\ Program Studi Manajemen Logistik, Institut Ilmu Sosial dan Manajemen STIAMI \\ Jl. Pangkalan Asem Raya No. 55, Cempaka Putih, Jakarta Pusat, Indonesia \\ dosenresistaok@gmail.com
}

Diterima: 09-02-2021

Disetujui: 16-06-2021

Dipublikasi: 31-06-2021

\begin{abstract}
ABSTRAK
Dealer Era Motor Tambun Yamaha adalah sebuah perusahaan yang bergerak dalam bidang penjualan berbagai jenis sepeda motor yamaha. Permasalahan yang sering dihadapi gudang adalah banyaknya suku cadang yang tidak tertampung dalam slotnya, jenis suku cadang yang sama ditempatkan di lebih dari satu lokasi, dan tidak adanya lokasi penyimpanan permanen, sehingga karyawan seringkali kesulitan dalam mencari suku cadang yang dibutuhkan. Penelitian tersebut bertujuan untuk memberikan perbaikan tata letak suku cadang. Suku cadang yang disimpan akan ditempatkan di lokasi permanen untuk memperlancar proses penyimpanan dan pengambilan suku cadang dari gudang dengan cara menjaga area gudang yang ada dengan menggunakan metode Dedicated Storage sehingga pemanfaatan area penyimpanan di gudang menjadi lebih optimal. Penempatan didasarkan pada perbandingan aktivitas tiap bagian dengan kebutuhan spasial yang dibutuhkan oleh bagian tersebut. Jadi, sebenarnya berapa luas sebenarnya yang dibutuhkan gudang suku cadang bisa diketahui. Dengan adanya desain blok baru dengan metode penyimpanan khusus diharapkan dapat meminimalkan suku cadang menempati lokasi permanen sehingga memudahkan karyawan dalam menyimpan dan mengambil suku cadang, sehingga arus keluar-masuk suku cadang menjadi lancar. Lebih lanjut, dari hasil penelitian dapat disimpulkan bahwa rasio luas blok meningkat menjadi $88,8 \%$ dari luas blok saat ini yang hanya $55,5 \%$. Selain itu didapat juga desain blok baru ukuran 10x2x3 meter dan desain layout dengan total luas lantai bekas 176 meter dengan total jarak tempuh 50 meter / hari.
\end{abstract}

Kata Kunci:

Tata Letak Gudang; Penyimpanan Khusus; Suku Cadang; Dealer

\begin{abstract}
Era Motor Tambun Yamaha Dealer was a company running in field of sales of various types of Yamaha motorcycles. The problems frequently faced by warehouses were the great number of parts not accommodated in the slots, same types of parts placed in more than one location, and the absence of permanent storage location, so employees frequently faced difficulties in finding required parts. The study aimed to provide spare-part layout improvement. The parts stored would be placed in permanent locations to expedite the process of storage and taking of parts from the warehouse by maintaining the existing warehouse area using Dedicated Storage method so the use of storage area in the warehouse became more optimal. The placement was based on comparison of activities of each part with spatial requirement needed by the parts. Therefore, how much actually was the area needed by spare-part warehouse could be found out. With the design of new blocks using dedicated storage methods, it was expected to minimize that the parts could occupy permanent locations to facilitate the employees in storing and taking the parts, so the in-and-out flow of parts became smooth. Furthermore, from the result of the study, it could be concluded that the amount of ratio of block area increased into $88.8 \%$ from current block
\end{abstract}


area that was only $55.5 \%$. Besides that, it also obtained the design of new blocks with size of 10x2 $\times 3$ meters and layout design with total used floor area of 176 meters with total mileage of 50 meters/day..

Keywords:

Warehouse Layout; Dedicated Storage; Spare Parts; Dealer 


\section{PENDAHULUAN}

Gudang merupakan tempat penyimpanan barang dalam suatu perusahaan. Hampir semua sektor baik industri, perdagangan, kuliner bahkan perbankan membutuhkan gudang dalam menjalankan usahanya. Bidang perdagangan seperti retail juga membutuhkan gudang untuk menyimpan barang dagangan nya. Karena fungsinya sebagai penyimpanan, semua kegiatan yang terjadi harus di lakukan dengan efektif dan efisien demi menunjang kegiatan operasional perusahaan. Selain itu, gudang yang baik harus dapat mempermudah tujuan utama gudang tersebut. Tujuan utama dari gudang adalah untuk memenuhi kebutuhan konsumen. Salah satu aspek yang yang dapat mempengaruhi efektifitas dan efesiensi gudang adalah layout gudang. Pada bagian gudang sparepart yang menyimpan 1000 item lebih part, di gudang penyimpanan terdapat permasalahan diantaranya tidak adanya area penerimaan sparepart yang baru saja datang sehingga banyak part yang tidak tertampung dalam gudang lalu sparepart di letakan di sembarang tempat, terdapat penempatan produk yang kurang tepat. Peletakan part yang baru saja datang di posisikan dekat dari pintu gudang, hal ini dikarenakan part merupakan material yang paling banyak proses material handling nya, baik masuk maupun keluar. Posisi yang dekat dengan pintu ini berpotensi mengganggu lalu lintas keluar masuk baik manusia maupun barang, sehingga perlu dilakukan penataan yang lebih baik dan dengan memperhatikan jalur pergerakan manusia dan barang. Layout gudang yang tidak teratur serta ukuran gudang yang kecil mengakibatkan terjadinya beberapa masalah pada gudang sparepart Era Motor. Beberapa pegawai sering kesulitan saat menjalankan aktivitas pencarian part di gudang. Pengaturan layout barang juga di butuhkan untuk mempermudah pencarian barang. Beberapa permasalahan yang sering terjadi di dalam gudang bengkel ialah: Pada saat barang datang dan sudah dilakukan pemeriksaan terhadap jumlah, pegawai meletakan di rak yang kosong, sehingga part yang di letakan bisa tercampur dengan item yang lain nya, barang yang seharusnya di letakan di rak masih sering kali di letakan di lantai dengan alasan rak sudah tidak menampung part yang baru datang, bahkan ada tumpukan barang yang melebihi kapasitas tumpukan dengan alasan sempitnya ruang gudang dan part diletakan di tempat yang tidak tetap atau berubahubah.

Ada beberapa metode yang dapat digunakan untuk menyimpan produk di gudang seperti class based storage, shared storage, Muther's Sytematic Layout Planning (SLP), serta dedicated storage. Metode Dedicated Storage (fixed location) memiliki kelebihan yakni setiap produk memiliki lokasi penyimpanan yang tetap. Hal ini dimaksudkan untuk menyelesaikan permasalahan tentunya mampu membuat total jarak material handling menjadi lebih pendek. Kekurangan metode ini adalah utilisasi ruang rendah karna lokasi produk tidak dapat di ubah-ubah atau digunakan oleh produk yang lain walaupun lokasi tersebut kosong.

Penelitian mengenai layout gudang dengan menggunakan metode dedicated storage telah banyak diteliti. Hasil penelitian tentang tata letak penyimpanan barang di gudang guna reduksi jarak tempuh, menghasilkan penurunan $12,27 \%$, setelah menerapkan metode dedicated storage (Kartika \& $\underline{\text { Helvianto, 2018). Selain itu, pada penelitian lain, penggunaan metode dedicated storage menunjukkan }}$ 
jarak material handling mengalami penurunanan sekitar $35,924 \%$ dari jarak sebelumnya (Prasetyaningtyas et al., 2013). Beberapa penelitian sejenis juga menghasilkan luaran yang sama, bahwa dengan penerapan metode dedicated storage, mampu menjadikan tata letak atau layout gudang lebih rapi dan teratur (Angelia et al., 2020; Efrataditama \& Wigati, 2016; Husin, 2020; Kemala \& Karo Karo, 2011).

Berdasarkan permasalahan gudang sparepart pada penelitian ini, penyelesaian yang dinilai tepat berdasarkan hasil pengamatan awal di gudang adalah dengan menggunakan metode Dedicated Storage. Sehingga penelitian ini bertujuan merancang ulang layout gudang dan menentukan kebutuhan luas area gudang. Dengan adanya penelitian ini diharapkan Gudang Sparepart Era Motor Yamaha menjadi lebih rapi dan teratur sehingga memudahkan aktivitas material handling dalam penyimpanan dan pengambilan produk, serta memudahkan karyawan dalam proses pencarian produk.

Gudang adalah bangunan yang dipergunakan untuk menyimpan barang dagangan. Pergudangan ialah kegiatan menyimpan dalam gudang (Angelia et al., 2020; Leopatria \& T, 2013). Jadi gudang adalah suatu tempat yang digunakan untuk barang baik yang berupa raw material, work in process, dan finished good. Pengertian gudang yang ada di dalam pergudangan yang berarti merupakan suatu kegiatan yang berkaitan dengan gudang (Warman, 2012). Pergudangan adalah segala upaya pengelolaan gudang yang meliputi penerimaan, penyimpanan, pemeliharaan, pendistribusian, pengendalian dan pemusnahan serta pelaporan logistik dan peralatan logistik agar kualitas dan kuantitas tetap terjamin (Asosiasi Logistik Indonesia).

Sedangkan layout merupakan satu keputusan penting yang menentukan efesiensi sebuah operasi dalam jangka panjang. Layout memiliki banyak dampak strategis karena layout menentukan daya saing perusahaan dalam segi kapasitas, proses, fleksibilitas, dan biaya, serta kualitas lingkungan kerja, kontak pelanggan, dan citra perusahaan. Layout yang efektif dapat membatu organisasi mencapai suatu strategi yang menunjang diferensiasi, biaya rendah atau respon cepat. Tujuan strategi layout adalah untuk membangun layout yang ekonomis yang memenuhi kebutuhan persaingan perusahaan. (Heizer \& Render, 2016)

Tujuan layout gudang adalah untuk menemukan titik optimal diantara biaya penanganan bahan dan biaya-biaya yang berkaitan dengan luas ruang dalam gudang. Sebagai konsekuensinya, tugas manajemen adalah memaksimalkan penggunaan setiap kotak dalam gudang yaitu memanfaatkan volume penuhnya sambil mempertahankan biaya penanganan part yang rendah (Mason et al., 2003).

Biaya penanganan part adalah biaya-biaya yang berkaitan dengan transportasi barang masuk, penyimpanan dan transportasi part yang keluar untuk dimasukkan dalam gudang. Biaya ini meliputi peralatan, orang, bahan, pengawasan, asuransi, dan penyusutan. Layout gudang yang efektif juga meminimalkan kerusakan bahan dalam gudang. Metode Dedicated Storage memiliki ciri setiap jenis barang disimpan di sebuah lokasi atau lokasi tertentu. Metode Dedicated Storage adalah metode yang digunakan dalam merancang ulang sebuah layout. Pada metode ini setiap produk di tempatkan pada suatu lokasi penyimpanan yang tetap. Jika suatu produk akan disimpan atau diambil, maka dapat dengan 
mudah tempatnya diketahui (Tompkins, 2010). Penyediaan tempat untuk setiap itemnya dapat diketahui dari persediaan maksimumnya. Metode ini memiliki kebijakan dalam menempatkan satu jenis item di tempat yang khusus hanya untuk item tersebut.

\section{METODE RISET}

Penelitian ini menggunakan pendekatan kuantitatif, dengan jenis penelitian deskriptif.

\section{Teknik Pengumpulan Data}

Data yang dilakukan adalah data primer dan sekunder, dengan rincian:

1. Data Primer

Yaitu data yang diperoleh langsung melalui pengamatan pencatatan yang di lakukan di Gudang Bengkel Yamaha Era Motor. Data untuk penyusunan laporan penelitian yang dilakukan adalah selama 7 bulan (Juni- Desember 2019), meliputi data:
a) Nama Part
b) Data Barang Masuk
c) Data Barang Keluar
d) Data Kapasitas Blok Gudang pada Kondisi Awal

2. Data Sekunder berupa Profil Usaha

Teknik Pengumpulan Data dilakukan dengan cara observasi dan wawancara terhadap petugas terkait. Teknik analisis data yang digunakan oleh peneliti dalam melakukan penelitian ini berdasarkan metode Dedicated Storage adalah sebagai berikut:

1) Menghitung Frekuensi Penerimaan dan Pengeluaran Part

Pengaturan gudang dilakukan berdasarkan nilai maksimum part yang diterima, yang di keluarkan dan stock akhir perhari dalam tujuh bulan terakhir. Pertimbangan penggunaan nilai maksimum tersebut dilakukan agar gudang mampu menyediakan area penyimpanan yang memadai untuk menyimpan part dalam kondisi maksimum sehingga kekurangan area penyimpanan produk dapat dihindari dan fleksibilitas luas gudang dapat tercapai.

2) Perhitungan Kebutuhan Slot

Slot adalah tempat penyimpanan produk di gudang. Agar seluruh part dapat di simpan ke slot, maka di butuhkan jumlah slot yang memadai untuk menempatkan part. Tinggi tumpukan juga di pertimbangkan dalam penentuan jumlah slot.

3) Perhitungan rasio frekuensi penerimaan dan pengeluaran dan kebutuhan slot

Setelah menghitung nilai frekuensi penerimaan dan pengeluaran part dan kebutuhan slot produk tahap berikutnya adalah menentukan nilai rasio nya. Nilai rasio dalam satu sub kelas selanjutnya di jumlahkan dan di peroleh total nilai rasio sub kelas. Total nilai rasio sub kelas akan dijadikan nilai rasio kelas produk. Kemudian rasio yang di peroleh di urutkan nilainya dari yang terbesar sampai terkecil. 
4) Perhitungan Jarak tempuh dari titik I/ O i ke Slot Part

Jumlah titik input / output itu ( $\mathrm{i}=1$ ) dan terletak di tengah-tengah sisi panjang gudang. Jarak yang di tempuh oleh part yang akan di simpan atau di ambil dari slot tertentu diukur dengan metode rectilinear.

$$
d_{i j}=\left|x_{i}-x_{j}\right|+\left|y_{i}-y_{j}\right|
$$

5) Penugasan setiap Part ke slot yang tersedia

Produk dengan rasio terbesar akan di tempatkan di slot dengan jarak terpendek, secara teknis cara penempatan seperti ini bertujuan untuk meminimasi jarak tempuh dari titik input/output ke slot, penempatan produk ke slot yang telah di tentukan di usahakan untuk selalu menghindari kemungkinan adanya produk dalam kelas yang sama di tempatkan terpisah. Namun dengan keterbatasan slot pada storage island (kumpulan slot penempatan produk) yang terbentuk dengan pertimbangan kelancaran akses penyimpanan dan pengambilan part, prinsip tersebut tidak sepenuhnya di terapkan dalam penempatan produk secara keseluruhan.

6) Perhitungan expected distance traveled

Perhitungan ekspektasi total jarak tempuh untuk kedua alternatif pengaturan dilakukan dengan menggunakan metode rectilinear. Perhitungan selanjutnya akan berujung pada penentuan jarak perpindahan produk dari slot ke titik input/ output. Berdasarkan perhitungan jarak dengan melakukan penyesuaian pada alokasi gang pemindahan part dan pengaturan storage island di gudang baru menggunakan metode aisle distance.

\section{Lokasi Penelitian}

Lokasi penelitian ini dilakukan di Dealer Yamaha Era Motor yang beralamat di Jl. Teuku Umar no 8 Tambun-Bekasi 17510.

\section{HASIL PENELITIAN DAN PEMBAHASAN}

\section{Hasil Penelitian}

Penelitian ini mengambil 10 jenis nama di mana part tersebut tergolong dalam part yang sifatnya Fast Moving data yang diperoleh dalam penelitian ini dapat dilihat sebagai berikut :

Tabel 1 Kapasitas BlokGudang Awal

\begin{tabular}{ccccc}
\hline Blok & Panjang & Lebar & Tingoj & Kapasitas Blok \\
\hline 1 & 10 & 2 & 2 & 40 slot \\
\hline 2 & 10 & 2 & 2 & 40 slot \\
\hline 3 & 10 & 2 & 2 & 40 slot \\
\hline 4 & 10 & 2 & 2 & 40 slot
\end{tabular}

Sumber: Data Gudang Bengkel Yamaha Era Motor (2019) 
Agustina, I. \& Vikaliana, R. (2021). Analisis Pengaturan Layout Gudang Sparepart ....

Tabel 2 Nama Part

\begin{tabular}{ccc}
\hline NO & NAMA PART & KODE PART \\
\hline 1 & Air Radiator & 90793 AJ802 \\
\hline 2 & Bulb Head Light & 54PA431410 \\
\hline 3 & Busi & 9470000415 \\
\hline 4 & Filter Oli & 1S7E3440 \\
\hline 5 & Filter Udara & 2DPE445100 \\
\hline 6 & Kampas Rem & 5YPF580501 \\
\hline 7 & Oli Garden & 90793AJ839 \\
\hline 8 & Oli Mesin & 90793AJ415 \\
\hline 9 & Oli Shock & 90793AJ821 \\
\hline 10 & Van-belt & 2DPWE76J0100
\end{tabular}

Sumber: Data Sparepart Bengkel Yamaha Era Motor (2019)

Tabel 3 Data Barang Masuk

No Nama Part Jun- Jul- Ags- Sep- Okt- Nov- Des-

\begin{tabular}{ccccccccc}
\hline 1. & Air Radiator & 12 & 24 & 48 & 12 & 24 & 12 & 24 \\
\hline 2. & Bullb Head Light & 10 & 15 & 30 & 10 & 10 & 10 & 15
\end{tabular}

\begin{tabular}{ccccccccc}
\hline 3. & Busi & 10 & 10 & 40 & 0 & 10 & 0 & 10 \\
\hline 4. & Filter 0li & 20 & 20 & 50 & 20 & 20 & 10 & 20 \\
\hline 5. & Filter Udara & 20 & 60 & 40 & 60 & 60 & 40 & 60 \\
\hline 6. & Kampas Rem & 80 & 100 & 120 & 90 & 50 & 90 & 100 \\
\hline 7. & Oli Garden & 144 & 96 & 144 & 144 & 96 & 144 & 144 \\
\hline 8. & Oli Mesin & 180 & 240 & 324 & 240 & 240 & 240 & 300 \\
\hline 9. & Oli Shock & 48 & 24 & 24 & 48 & 0 & 24 & 48 \\
\hline 10. & Van-Belt & 10 & 20 & 15 & 10 & 10 & 20 & 20
\end{tabular}

Sumber: Data Sparepart Masuk Bengkel Yamaha Era Motor (2019)

Tabel 4 Data Barang Keluar

No Nama Part Jun- Jul- Aggs- Sep- Okt- Nov- Des2019201920192019201920192019

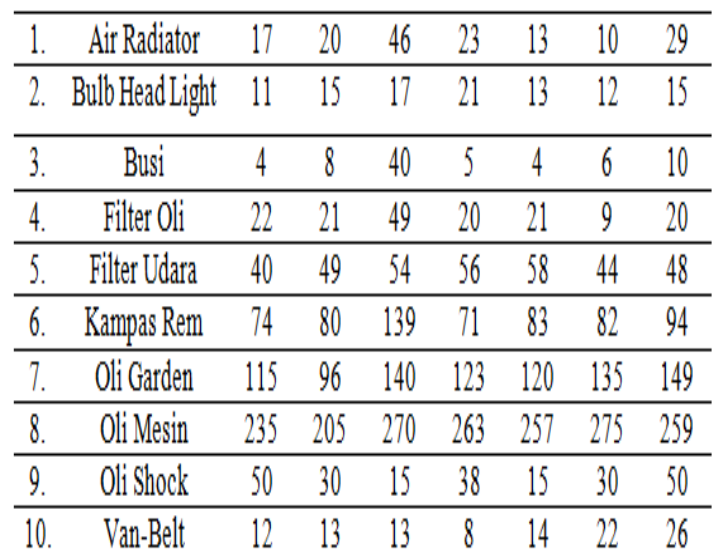

Sumber: Data Sparepart Keluar Bengkel Yamaha Era Motor (2019) 


\section{Persentase Rasio Luas Blok}

$=\frac{\text { luas area gudang yang terpakai }}{\text { luas area gudang }} \times 100 \%$

Persentase rasio luas Blok $=\frac{110}{198} \times 100 \%$

Persentase rasio luas Blok $=55,5 \%$

Berdasarkan penghitungan, maka persentase rasio luas blok gudang adalah 55,5\%.

\section{Menghitung Frekuensi Penerimaan dan Pengeluaran Part $\left(T_{j}\right)$}

a. Diketahui dalam 7 bulan terakhirpenerimaan/pengeluaran rata-rata perbulan untuk Part Oli mesin adalah 252 dan 252 sedangkan sekali pemindahan dengan menggunakan troli dapat memindahkan 4 dus per maka besarnya Troughput untuk Part Oli Mesin adalah :

$\mathrm{T}=($ Penerimaan Rata-rata + Pengeluaran Rata- rata $) / 4$

$\mathrm{T}=(21+21) / 4_{-}=11$ aktivitas

b. Diketahui dalam 7 bulan terakhir penerimaan/pengeluaran rata-rata perbulan untuk Part Oli Garden adalah 130 dan 125 sedangkan sekali pemindahan dengan menggunakan troli dapat memindahkan 4 dus maka besarnya Troughput untuk Part Oli Garden adalah :

$\mathrm{T}=($ Penerimaan Rata-rata + Pengeluaran Rata- rata $) / 4$

$\mathrm{T}=(11+11) / 4_{-}=6$ aktivitas

c. Diketahui dalam 7 bulan terakhir penerimaan/pengeluaran rata-rata perbulan untuk Part kampas Rem adalah 90 dan 89 sedangkan sekali pemindahan dengan menggunakan troli dapat memindahkan 4 dus maka besarnya Troughput untuk Part Kampas Rem adalah :

$\mathrm{T}=($ Penerimaan Rata-rata + Pengeluaran Rata- rata $) / 4$

$\mathrm{T}=(9+9) / 4_{-}=5$ aktivitas

d. Diketahui dalam 7 bulan terakhir penerimaan/pengeluaran rata-rata perbulan untuk Part Oli Shock adalah 31 dan 33 sedangkan sekali pemindahan dengan menggunakan troli dapat memindahkan 5 dus maka besarnya Troughput untuk Part Oli Shock adalah :

$\mathrm{T}=($ Penerimaan Rata-rata + Pengeluaran Rata- rata $) / 5$

$\mathrm{T}=(5+5) / 5=2$ aktivitas

e. Diketahui dalam 7 bulan terakhir penerimaan/pengeluaran rata-rata perbulan untuk Part Filter Oli adalah 22 dan 23 sedangkan sekali pemindahan dengan menggunakan troli dapat memindahkan 5 dus maka besarnya Troughput untuk Part Filter Oli adalah :

$\mathrm{T}=($ Penerimaan Rata-rata + Pengeluaran Rata- rata $) / 5$

$\mathrm{T}=(22+23) / 4_{-}=9$ aktivitas

f. Diketahui dalam 7 bulan terakhir penerimaan/pengeluaran rata-rata perbulan untuk Part Air Radiator adalah 22 dan 23 sedangkan sekali pemindahan dengan menggunakan troli dapat memindahkan 5 dus maka besarnya Troughput untuk Part Air Radiator adalah :

$\mathrm{T}=($ Penerimaan Rata-rata + Pengeluaran Rata-rata $) / 5$

$\mathrm{T}=(22+23) / 5=9$ aktivitas 


\section{Menghitung Kebutuhan Slot $\left(S_{\mathbf{j}}\right)$}

Slot merupakan tempat penyimpanan produk di gudang. Luas gudang sebesar $198 \mathrm{~m}$ dengan lebar $18 \mathrm{~m}$ dan panjang $11 \mathrm{~m}$. Ukuran slot di gunakan berdasarkan rata-rata ukuran part penerimaan produk dan memberikan kemudahan dalam menentukan total slot yang di butuhkan oleh suatu part. Agar seluruh part dapat di simpan di slot maka, dibutuhkan jumlah slot yang memadai (feasible) untuk menempatkan part. Tinggi tumpukan juga dipertimbangkan dalam penentuan jumlah slot.

\section{Penghitungan Rasio Frekuensi Penerimaan, Pengeluaran dan Kebutuhan Slot}

Tabel 5 di bawah ini menunjukkan rasio frekuensi penerimaan, pengeluaran dan kebutuhan slot pada gudang.

Tabel 5 Rasio

\begin{tabular}{ccc}
\hline Urutan & Sub part & $T / S$ \\
\hline 1 & Oli Mesin & 504 \\
\hline 2 & Oli Garden & 255 \\
\hline 3 & Kampas Rem & 179 \\
\hline 4 & Filter Udara & 99 \\
\hline 5 & Oli Shock & 64 \\
\hline 7 & Filter Oli & 45 \\
\hline 8 & Air Radiator & 45 \\
\hline 9 & Van-belt & 30 \\
\hline 10 & Bulb Head Light & 29 \\
\hline
\end{tabular}

Sumber : Penghitungan Rasio Gudang (2019)

\section{Penghitungan Jarak Tempuh dari dari titik I/O ke slot Produk}

$$
d_{i j}=\left|x_{i}-x_{j}\right|+\left|y_{i}-y_{j}\right|
$$

\section{Penugasan Setiap Part ke Slot yang Tersedia}

Oli mesin adalah part yang memiliki nilai rasio terbesar yaitu 504 yang akan ditempatkan di Slot dengan jarak terpendek atau terkecil, part dengan nilai rasio terbesar ke 2 adalah Oli Garden yang memiliki nilai rasio 255 akan ditempatkan dengan jarak kedua terpendek dan seterusnya.

Berikut Tabel 6 yang menunjukkan jumlah kapasitas dan ukuran blok rancangan pada saat ini.

Tabel 6 Analisis Jumlah Kapasitas dan Ukuran Blok Rancangan Awal

\begin{tabular}{|c|c|c|c|c|c|c|}
\hline \multirow{3}{*}{ No } & \multicolumn{3}{|c|}{ Kapasitas Blok saat Ini } & \multicolumn{3}{|c|}{ Rancangan Kapasitas Blok } \\
\hline & Ukuran & Banyak & Kapasitas & Ukuryan & Banyak & Kapasitas \\
\hline & Blok & Blok & & Blok & Blok & \\
\hline 1 & $10 \times 2 \times 2$ & 1 & 40 slot & $10 \times 2 \times 3$ & 1 & 60 slot \\
\hline 2 & $10 \times 2 \times 2$ & 1 & 40 slot & $10 \times 2 \times 3$ & 1 & 60 slot \\
\hline 3 & $10 \times 2 \times 2$ & 1 & 40 slot & $10 \times 2 \times 3$ & 1 & 60 slot \\
\hline 4 & $10 \times 2 \times 2$ & 1 & 40 slot & $10 \times 2 \times 3$ & 1 & 60 slot \\
\hline$j$ & & & & $10 \times 2 \times 3$ & 1 & 60 slot \\
\hline Total & & 4 & 160 slot & Total & 5 & 300 slot \\
\hline
\end{tabular}

Sumber : Penghitungan Kapasitas dan Ukuran Blok Gudang (2019) 
Dari hasil penghitungan jumlah dan ukuran blok, kapasitas rancangan blok lebih besar dari kapasitas blok saat ini dengan selisih 140 part.

Persentase rasio luas Blok $=\frac{\text { luas area gudang yang terpakai }}{\text { luas area gudang }} \times 100 \%$

Persentase rasio luas Blok $=\frac{176}{198} \times 100 \%$

Persentase rasio luas Blok $=88,8 \%$

\section{Penghitungan Expected Distance Travelled}

Berdasarkan penghitungan jarak dengan melakukan penyesuaian pada alokasi gang pemindahan part di hitung dengan menggunakan metode aisle distance pengukuran jarak dengan menggunakan metode ini menghasilkan total jarak perpindahan sebesar $50 \mathrm{~m}$ per hari. Berikut ini merupakan gambar kondisi awal gudang dan rancangan gudang dengan menerapkan metode dedicated storage.
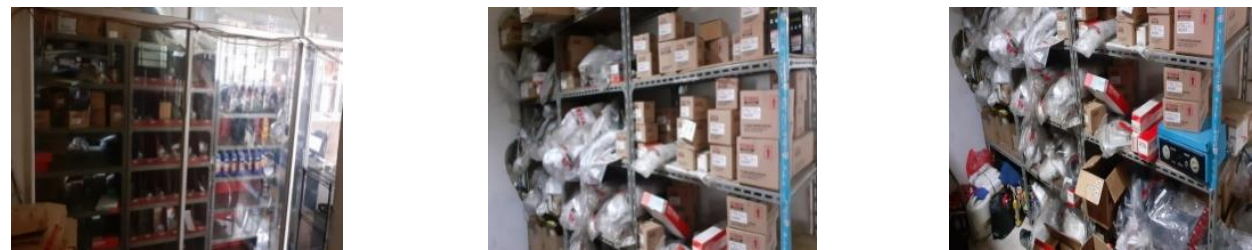

Gambar 1 Kondisi Gudang Saat Awal

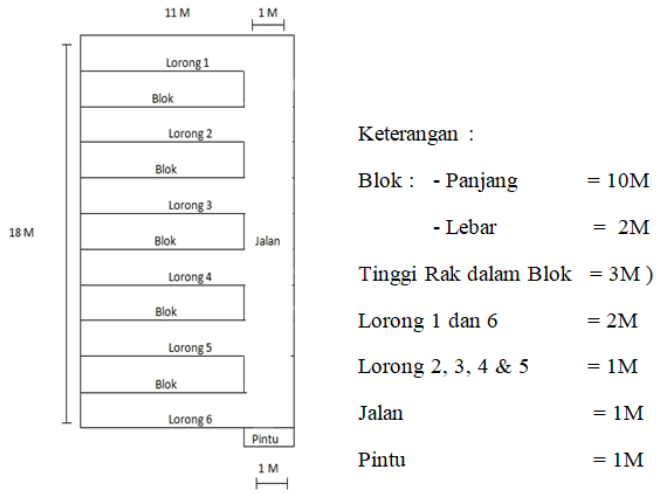

Gambar 2 Gudang Rancangan dengan Penerapan Metode Dedicated Storage

\section{Pembahasan}

\section{Analisis Rasio Luas Blok Terhadap Luas Gudang}

Rasio luas gudang saat ini lebih rendah dibandingkan analisa rasio luas gudang perbaikan karena layout gudang saat ini belum maksimal karna ruas jalan yang di gunakan oleh gudang saat ini sangat lebar semakin besar ruang kosong yang di pakai untuk ruas jalan tersebut tentunya kurang baik. Dari hasil penghitungan rasio luas blok terhadap rancangan luas blok perbaikan, diketahui bahwa besarnya rasio blok meningkat menjadi $88,8 \%$ dari besarnya blok saat ini yang sebesar 55,5\%. Dengan bertambahnya luas gudang yang digunakan untuk mendesain, maka besarnya lebar ruas jalan dapat dikurangi sehingga pemanfaatan gudang lebih besar. Meningkatnya besar kapasitas blok penyimpanan ini menjadi faktor yang dapat mereduksi timbulnya produk yang tidak tertampung. Hal ini serupa 
dengan penelitian terdahulu bahwa gudang menjadi lebih luas (Efrataditama \& Wigati, 2016; Husin, 2020).

\section{Hasil Penempatan Produk}

Oli mesin adalah part yang memiliki nilai rasio terbesar yaitu 504 yang akan di tempatkan di Slot dengan jarak terpendek atau terkecil 3 meter, part dengan nilai rasio terbesar ke 2 adalah Oli Garden yang memiliki nilai rasio 255 akan di tempatkan dengan jarak kedua terpendek 4,5 meter dan seterusnya. Penelitian lain yang telah dilakukan juga menunjukkan gudang menjadi lebih rapi karena penempatan produk lebih teratur (Efrataditama \& Wigati, 2016; Husin, 2020).

\section{Jarak Perjalanan Total}

Dari hasil penelitian diperoleh besarnya rasio luas blok meningkat menjadi 88,8\% dari besarnya rasio luas blok saat ini yang hanya sebesar 55,5\% dan di dapat hasil rancangan layout gudang memiliki total luas lantai terpakai sebesar 176 meter dengan total jarak tempuh 50 meter/ hari. Dengan mengetahui total luas lantai terpakai dan total jarak perpindahan tersebut Penempatan part yang akan disimpan akan menempati posisi yang tetap untuk menghindari adanya part dalam jenis yang sama diletakkan terpisah dari jenisnya, sehingga memudahkan pegawai dalam menyimpan dan mengambil part sehingga semuanya menjadi lebih efektif. Hasil ini sejalan dengan penelitian terdahulu bahwa penerapan metode dedicated storage akan mengurangi atau meminimalisir jarak tempuh (Kartika \& Helvianto, 2018; Prasetyaningtyas et al., 2013).

\section{KESIMPULAN DAN SARAN}

Kesimpulan dari hasil penelitian ini ialah:

1. Dari hasil analisa pengaturan layout gudang Sparepart didapatkan peningkatan rasio luas blok terhadap luas gudang sebesar 88,8\% dengan rincian 5 Blok dengan 2 macam ukuran, yang mampu menampung part lebih banyak. Dengan ini kapasitas penyimpanan part lebih besar dari pada kapasitas penyimpanan gudang saat ini.

2. Pengaturan layout gudang dengan metode Dedicated Storage ini lebih baik dari layout gudang yang ada sekarang karena penyimpanan part lebih efektif dan tidak menyulitkan pegawai dalam pencarian part.

Berdasarkan hasil penelitian ini, disarankan perusahaan dapat mengaplikasikan pengaturan layout gudang ini jika ingin melakukan pengaturan ulang. Selain itu, pengaturan ulang terhadap layout dan blok-blok penyimpanan part perlu dilakukan kembali supaya lebih efektif dan efisien. 


\section{DAFTAR PUSTAKA}

Angelia, F., Suhada, K., Studi, P., Industri, T., Kristen, U., \& Bandung, M. (2020). Perbaikan Tata Letak Gudang dengan Association Rule Mining dan Dedicated Storage Policy di PD Andika Indramayu. Journal of Integrated System Vol. 3 No. 2 (Desember 2020): Vol 3 No 2 (2020) 161179 .

Efrataditama, A. V., \& Wigati, S. S. (2016). Perancangan Tata Letak Gudang Dengan Metode Dedicated Storage Di Toko Listrik Anugrah Jaya. Seminar Nasional IENACO.

Heizer, J., \& Render, B. (2016). Manajemen Operasi (11th ed.). Salemba Empat.

Husin, S. (2020). Perbaikan Tata Letak Gudang Produk Jadi Dengan Metode Dedicated Storage Di Gudang PT . YYZ. Journal of Industrial and Systems Optimization, 3(1), 8-15.

Kartika, W., \& Helvianto, A. W. (2018). Ruang lingkup penelitian ini Untuk Reduksi Jarak Tempuh Perjalanan Material Handling adalah rata-rata penerimaan produk forklift. Jurnal Manajemen Industri dan Logistik . 56-70.

Kemala, W., \& Karo Karo, G. (2011). Usulan Perencanaan Tata Letak Gudang Produk Jadi Dengan Menggunakan Metode Muthers Systematic Layout Planning. Journal of Industrial Engineering and Management System, 4(2), 69-96.

Leopatria, M., \& T, H. C. P. S. (2013). Perancangan Sistem Manajemen Gudang Tepung di PT X. 1(2), 49-56. Petra International Journal of Business Studies. http://studentjournal.petra.ac.id/index.php/teknik-industri/article/download/976/875

Mason, S. J., Ribera, P. M., Farris, J. A., \& Kirk, R. G. (2003). Integrating the warehousing and transportation functions of the supply chain. Transportation Research Part E Logistics and Transportation Review 39(2):141-159

Prasetyaningtyas, A. A., Herlina, L., \& Ilhami, M. A. (2013). Usulan Tata Letak Gudang Untuk Meminimasi Jarak Material Handling Menggunakan Metode Dedicated Storage. Jurnal Teknik Industri, 1(1), 29-34.

Tompkins, J. A. (2010). Facilities Planning. Wiley.

Warman, J. (2012). Manajemen Pergudangan (Ketujuh). PT Puka Sinar Harapan. 